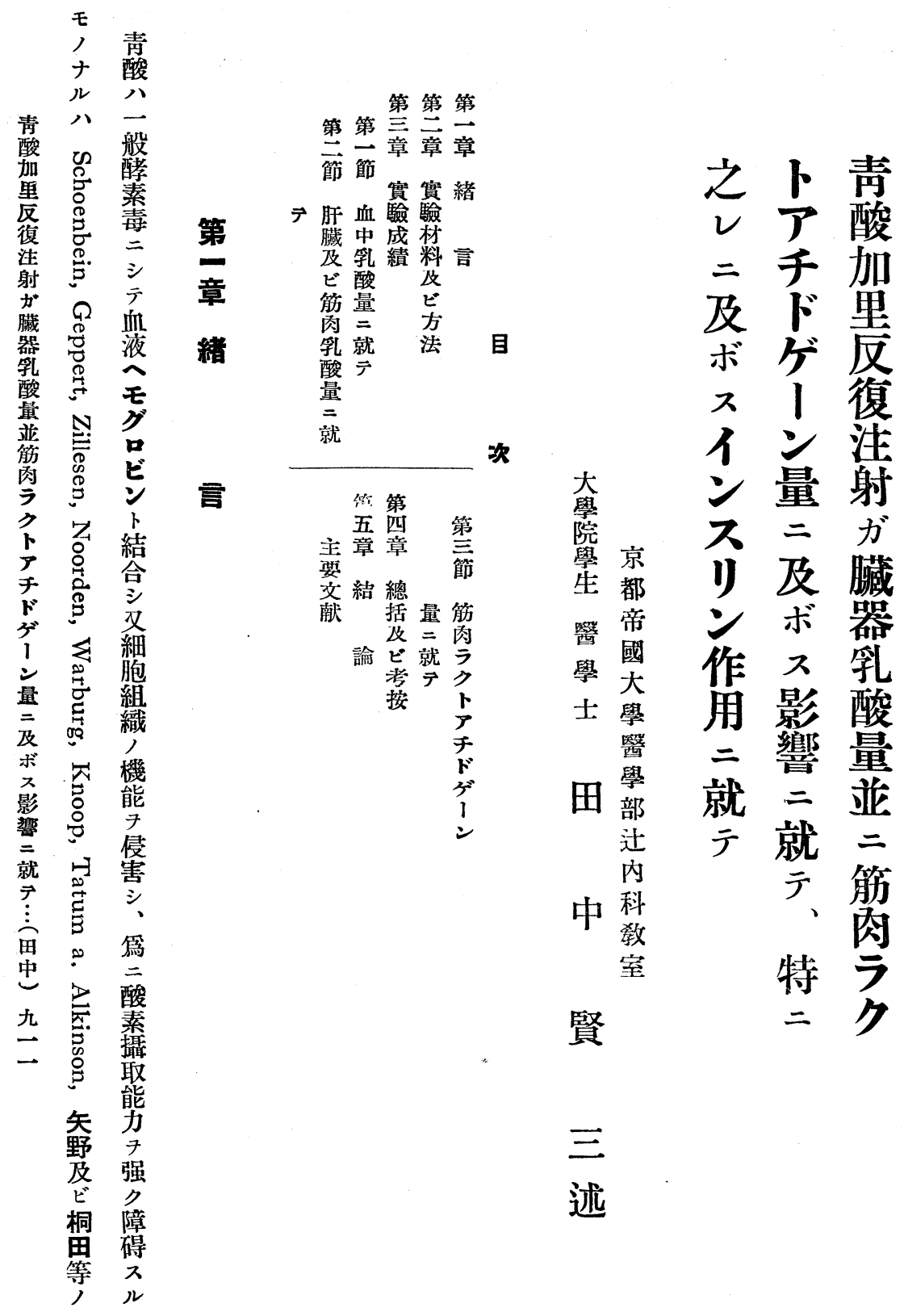




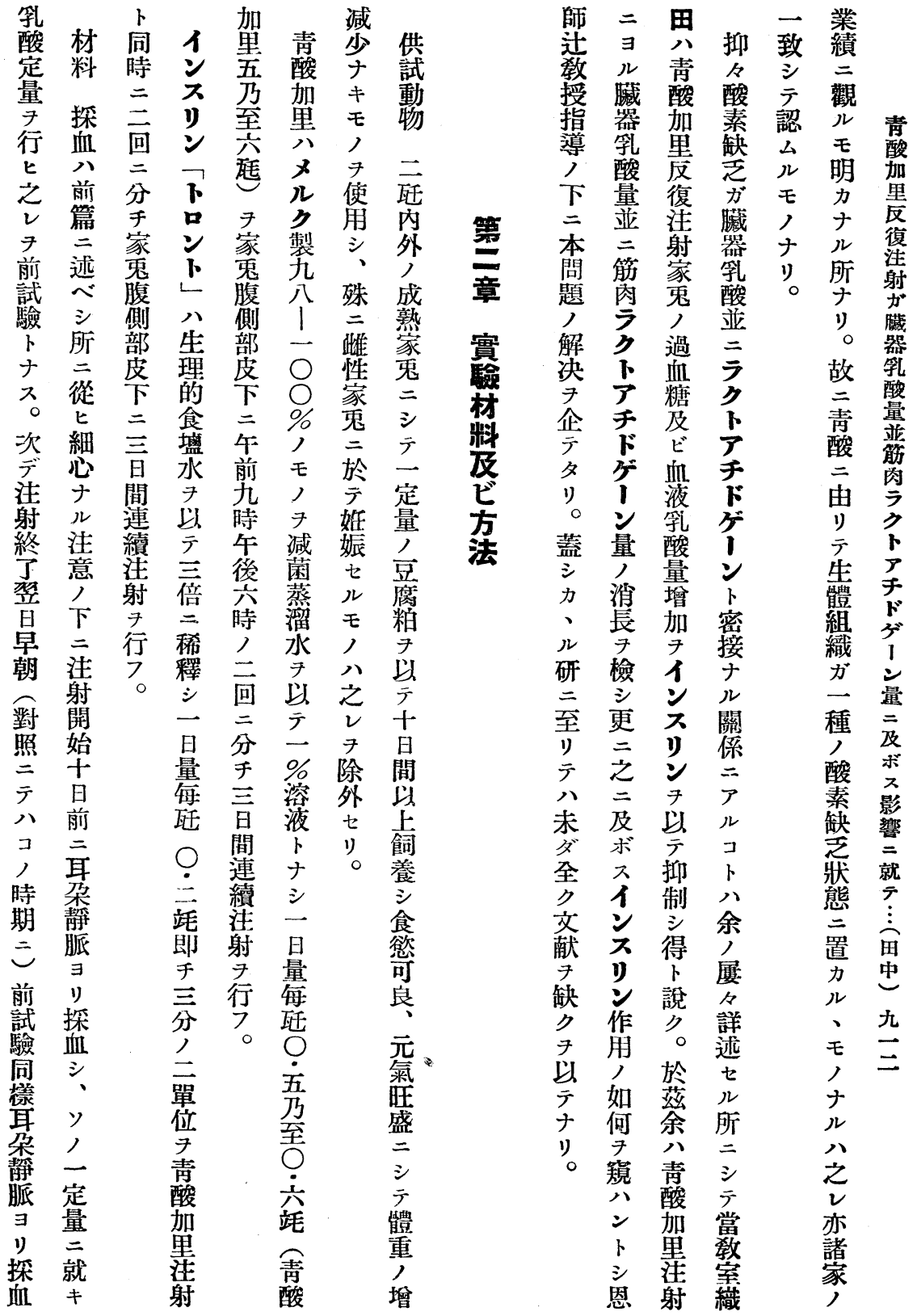



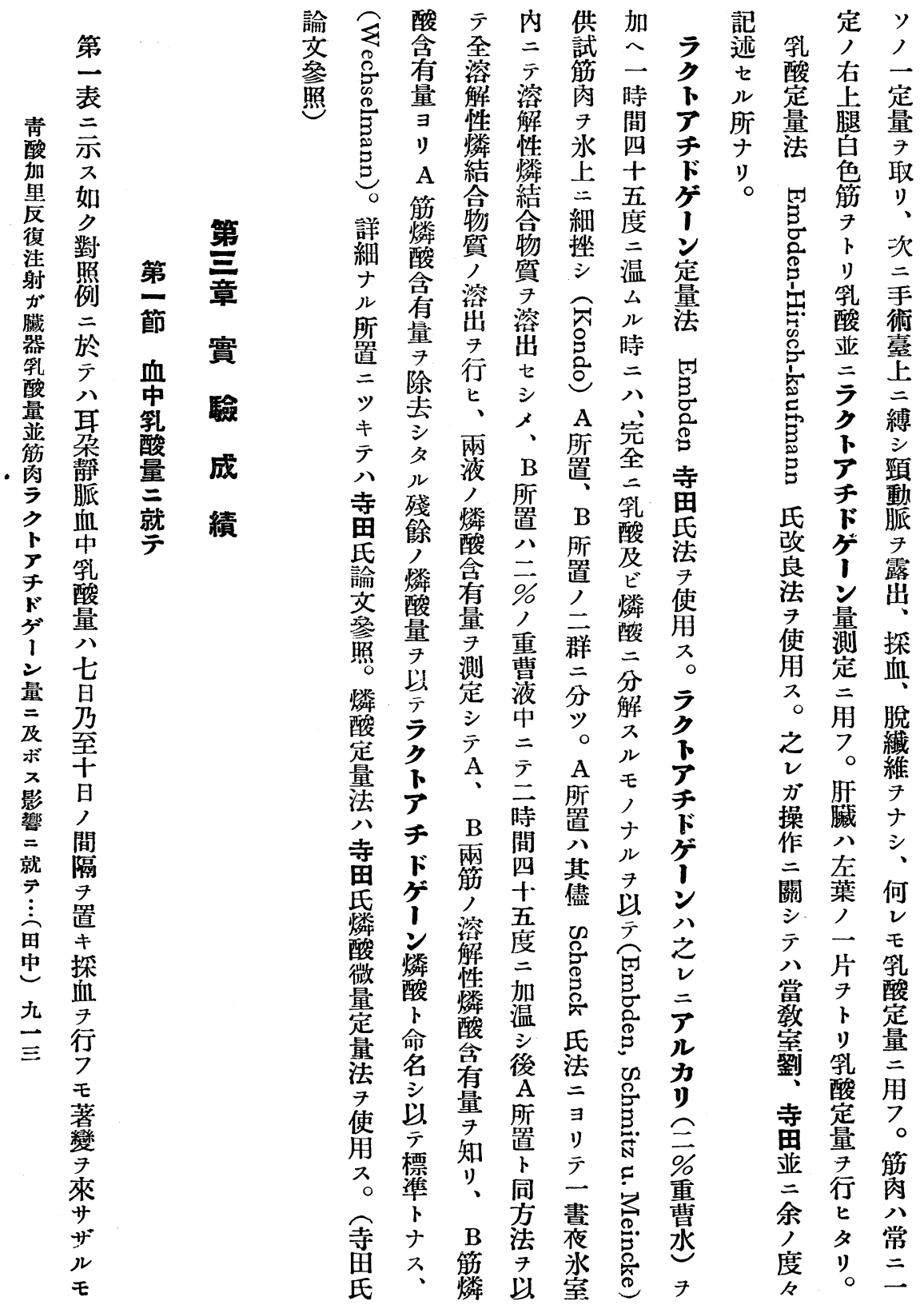

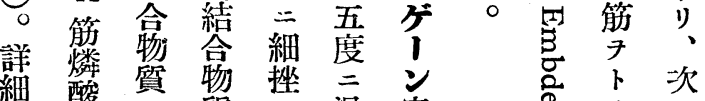

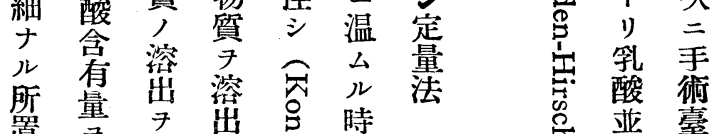

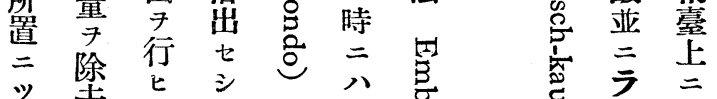
兴去

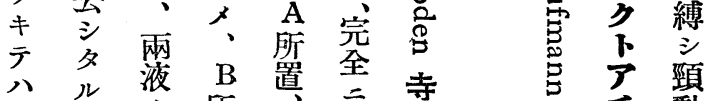

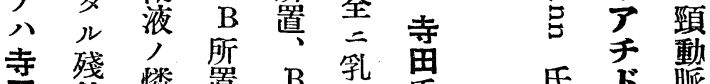

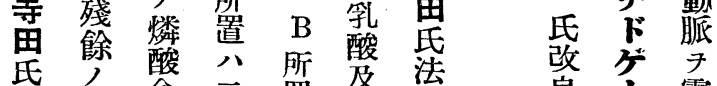

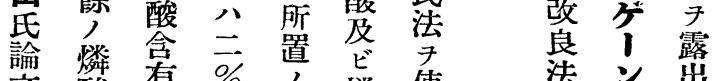
文酸郁 \% 厂燐使法量 參量 量重 群酸用使测探

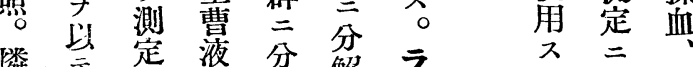

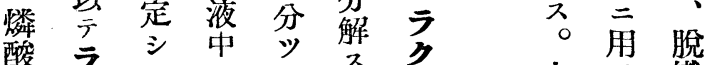
定

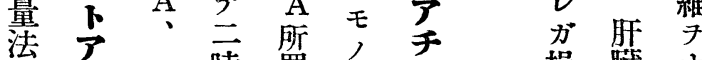

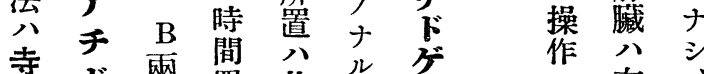

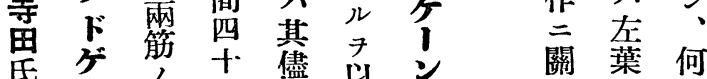

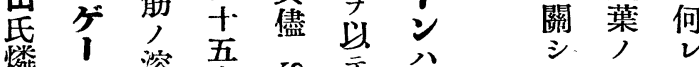

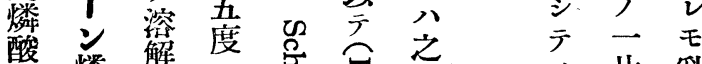
酸燐解㤩国之分片乳

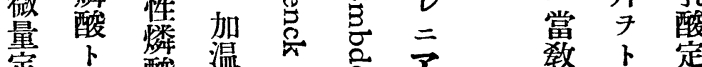

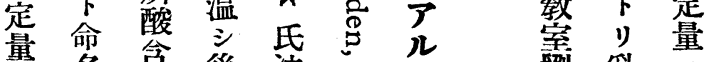
名拿後法江力 釷乳二 音量 $\mathrm{A}=$ 号 $\mathrm{J}$ 酸用 使 占量 置 用示知置 严 $\overrightarrow{0}$ 思量 ス 準 ”, 同

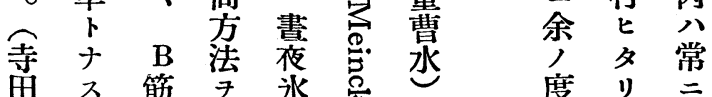

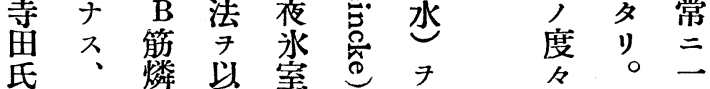




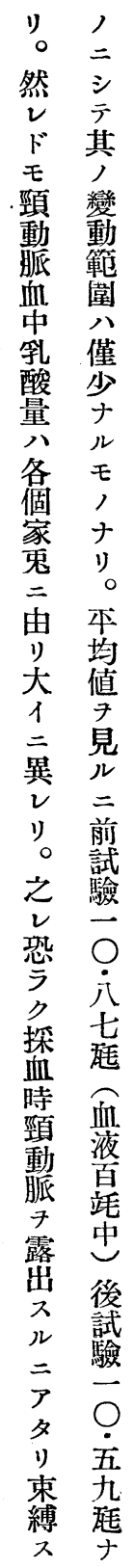

\begin{tabular}{|c|c|c|c|c|c|c|}
\hline 平 & 四 & $\equiv$ & 二 & $\rightarrow$ & \multicolumn{2}{|c|}{$\begin{array}{l}\text { 番 } \\
\text { 號 }\end{array}$} \\
\hline & & q & $q$ & ㅇ. & $i$ & E \\
\hline $\begin{array}{l}\text { 後前 } \\
\text { 試試譣驗 }\end{array}$ & $\begin{array}{l}\text { 後剪 } \\
\text { 試驗 } \\
\text { 驗 }\end{array}$ & $\begin{array}{l}\text { 後前 } \\
\text { 試 } \\
\text { 驗 } \text { 驗 }\end{array}$ & 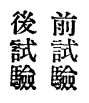 & $\begin{array}{l}\text { 後前 } \\
\text { 試 試 } \\
\text { 驗 驗 }\end{array}$ & & \\
\hline $\begin{array}{l}\text { 竞 } \\
\text { 西 } \\
\text { 妾 }\end{array}$ & $\begin{array}{l}\text { 音室 } \\
\text { 吾吾 } \\
\end{array}$ & $\begin{array}{l}\text { 辛 } \\
\text { 立 } \\
\text { 旮 } \\
\text { ○ }\end{array}$ & 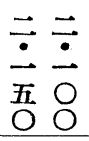 & 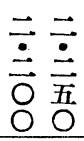 & 骨 & 豊 \\
\hline $\begin{array}{l}\overrightarrow{0} \overrightarrow{0} \\
\dot{\underline{T}} \dot{\lambda} \\
\text { t }\end{array}$ & $\begin{array}{l}\overrightarrow{0} \overrightarrow{0} \\
\dot{\theta} \\
\text { 至兵 }\end{array}$ & $\begin{array}{l}\text { 九 } \\
\text { 九 } \\
\text { 亲主 } \\
\text { 兵 }\end{array}$ & 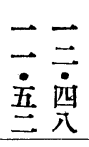 & 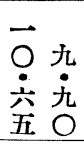 & 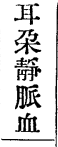 & $\begin{array}{l}\text { 乳 } \\
\text { 酸 } \\
\text { 芦覔 }\end{array}$ \\
\hline $\begin{array}{l}\text { 公 } \\
\text { 允 } \\
\dot{\vec{c}}\end{array}$ & $\begin{array}{l}八 \\
\vdots \\
\vdots \\
\vdots\end{array}$ & $\frac{\text { 公 }}{\text { 㐬 }}$ & $\begin{array}{l}\text { 五 } \\
\text { 突 } \\
\text { 畜 }\end{array}$ & $\begin{array}{l}\text { 五 } \\
\stackrel{0}{\dot{\pi}} \\
\dot{\pi}\end{array}$ & 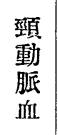 & $\begin{array}{l}\text { 量 } \\
\text { 誆 } \\
\text { \% }\end{array}$ \\
\hline
\end{tabular}




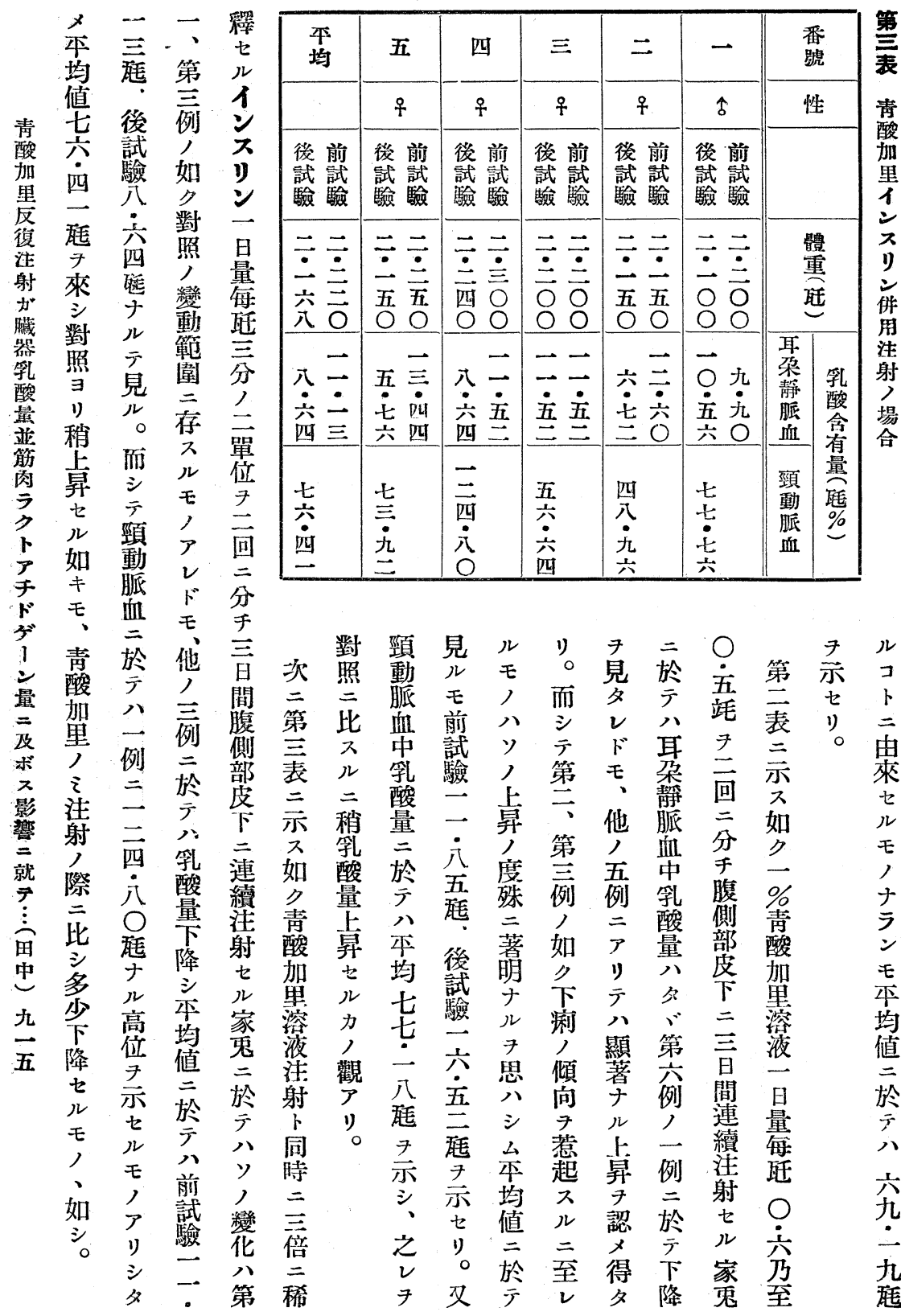




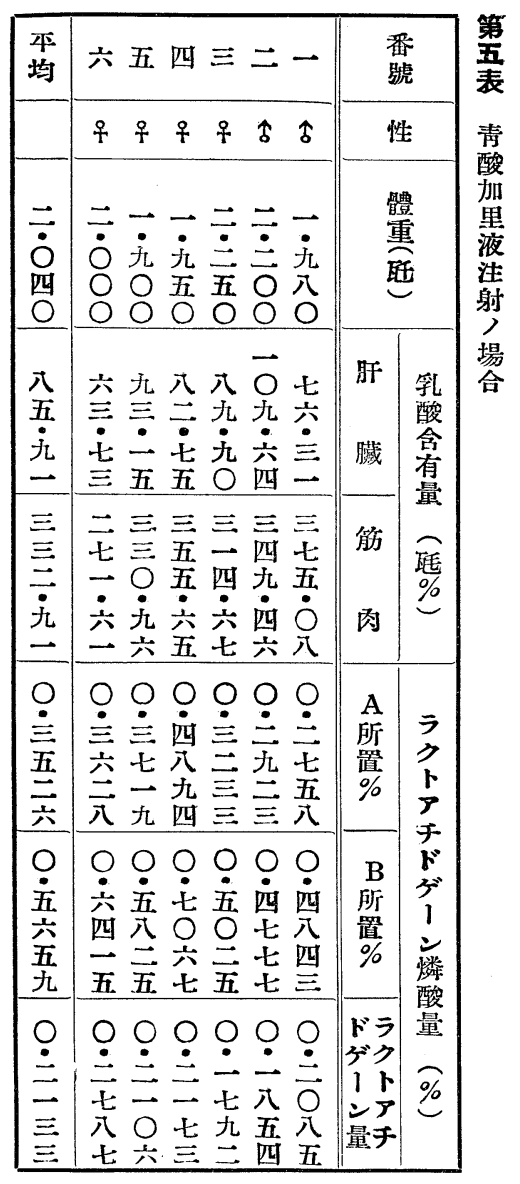



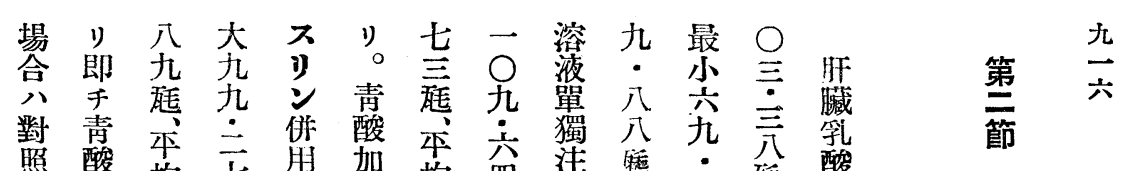

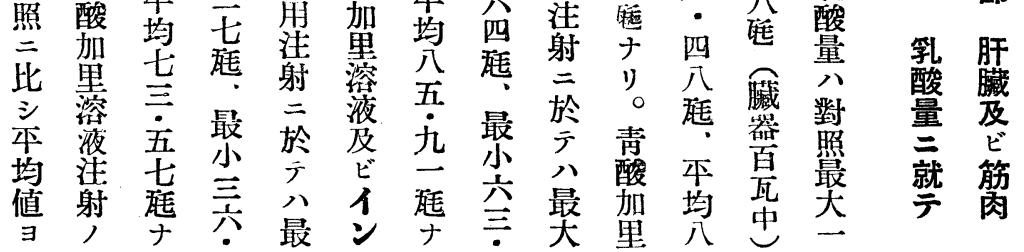



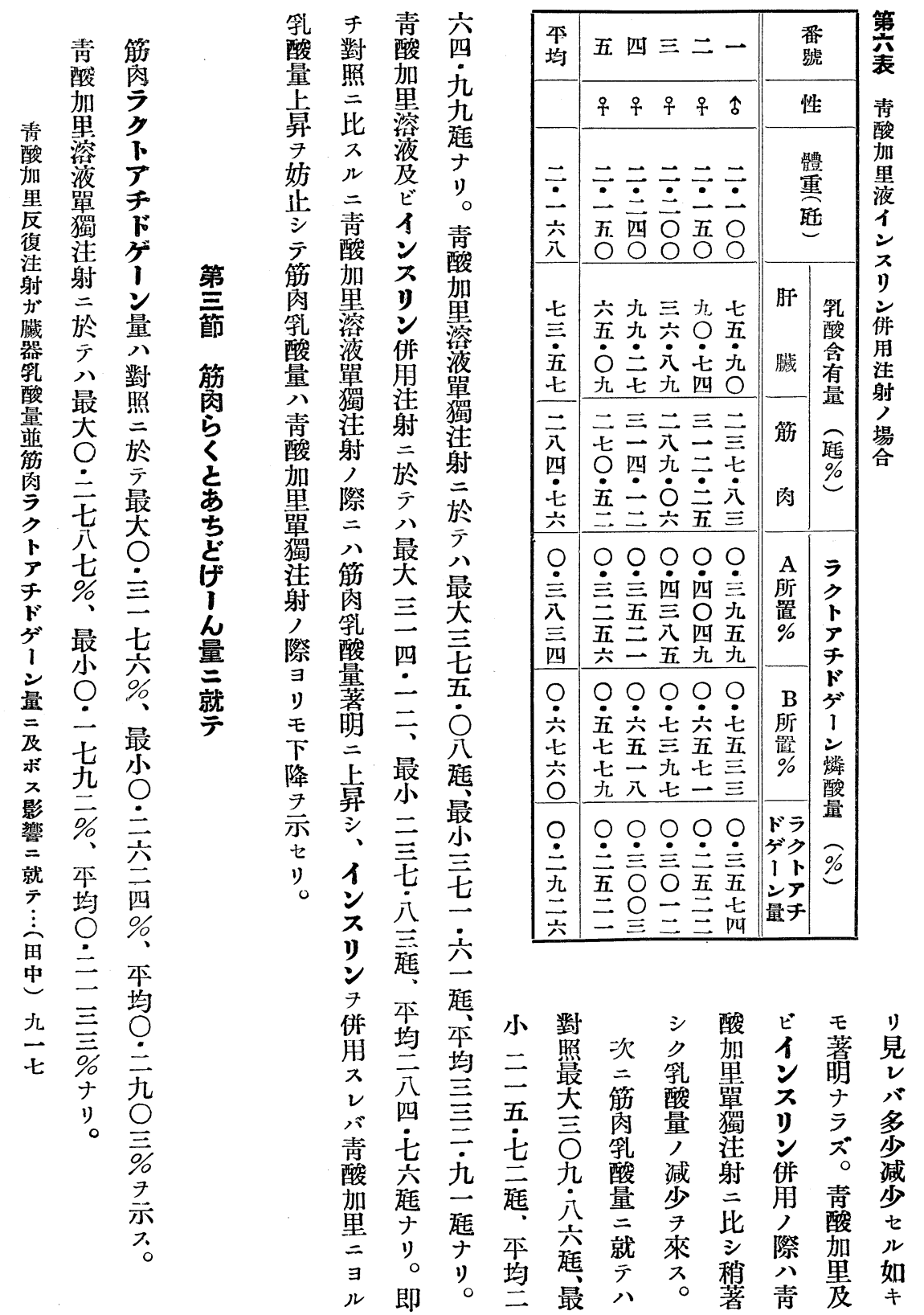


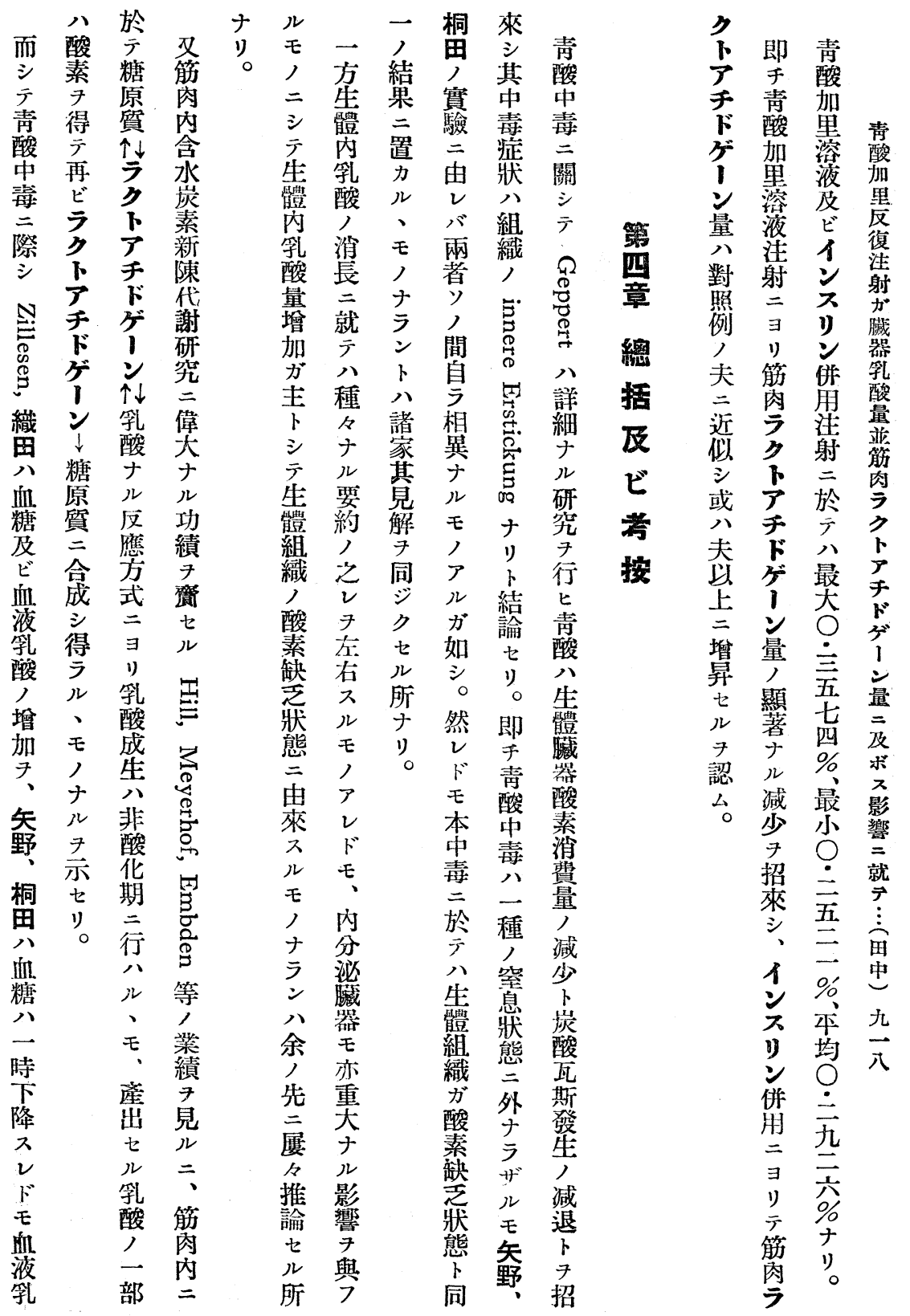




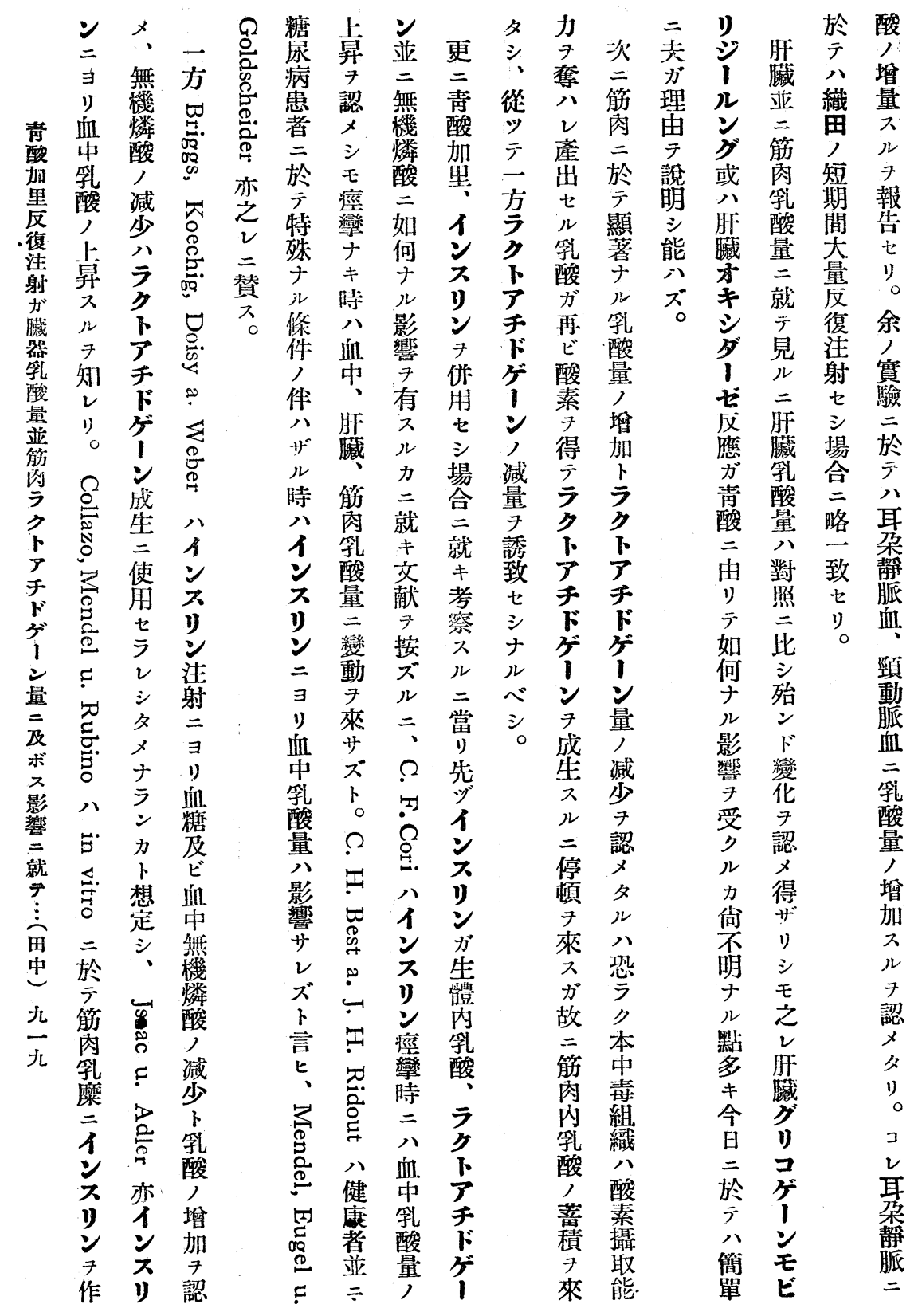




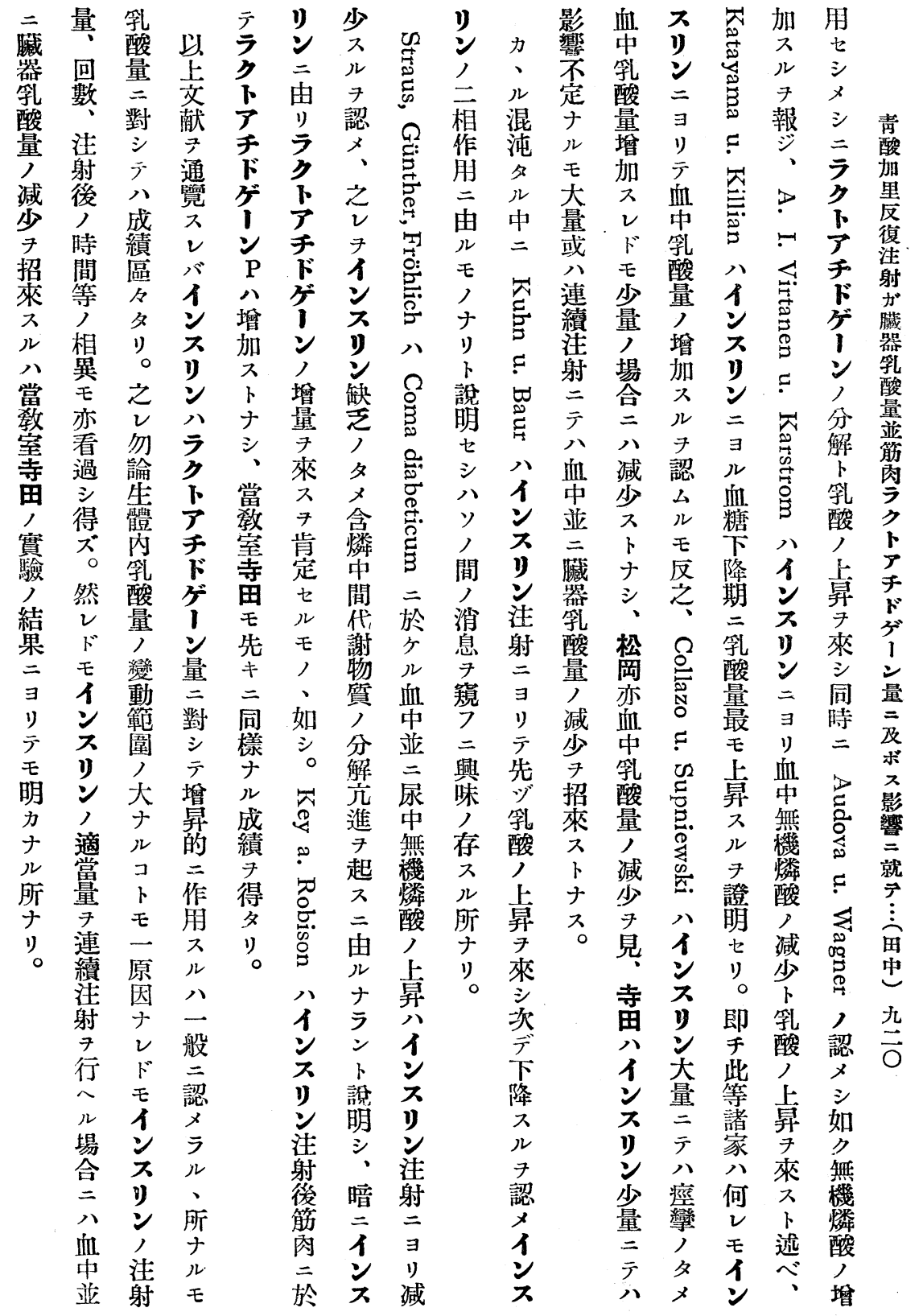




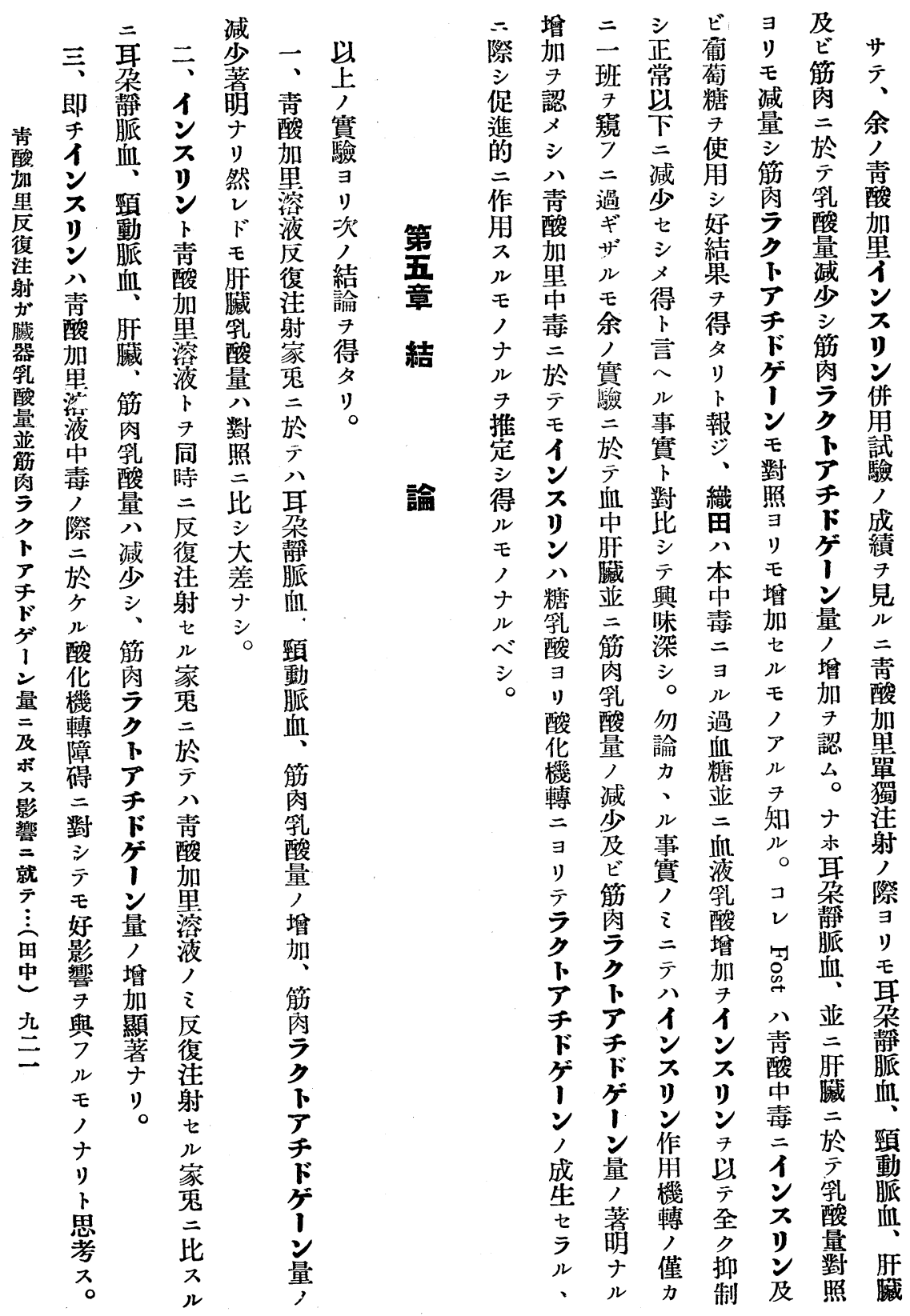




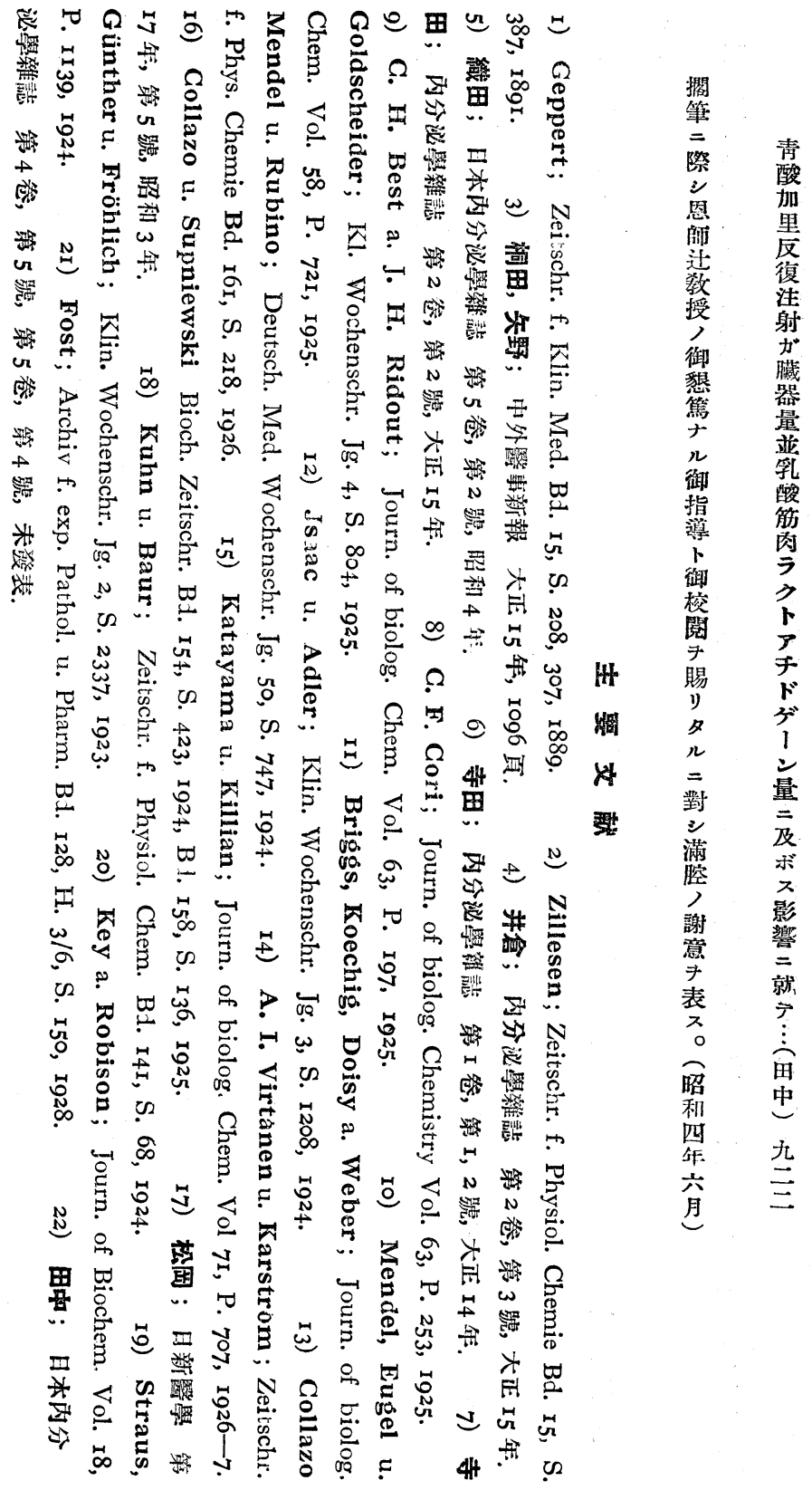


Daraus darf man schliessen, dass Milz und Schilddrüse bezüglich der Blutmilchsäure antagonistisch zueinander wirken.

(Autoreferat)

\title{
Ueber den Einfluss der chronischen Gyankaliver- giftung auf die Organmilchsäure und das \\ Lactacidogen des Muskels, insbesondere über die Beziehung der Gyankaliver- giftung zur Iusnlinwirkung.
}

\author{
Von \\ Dr. K. Tanaka. \\ (Aus der I. med. Klinik der Kaiserlichen Universität \\ zu Kyoto, Japan. Direktor: Prof. Dr. K. Tsuji.)
}

Die Resultate sind die folgenden:

I) Wiederholte subkutane Injektion von I \% iger Cyankalilösung bewirkt bei Kaninchen Vermehrung des Milchsäuregehaltes im Ohrvenenblute, Karotisblute und den weissen Muskeln des Oberschenkels sowie deutliche Verminderung des Lactacidogengehaltes dieser Muskel. Aber man sieht in bezug auf den Milchsäuregehalt der Leber keine deutliche Veränderung.

2) Bei gleichzeitig wiederholter Injektion von Cyankalilösung und Insulin zeigen Ohrvenenblut, Karotisblut, die Leber und der Muskel deutlichere Verminderung des Milchsäuregehaltes und der Muskel ausserdem beträchtlichere Vermehrung des Lactacidogen als bei wiederholter Injektion der Cyankalilösung allein.

3) Aus den oben beschriebenen Tatsachen darf man schliessen, dass Insulin auch anf die Oxydationsstörung bei der chronischen Cyankalivergiftung einen guten Einfluss |ausübt.

(Autoreferat). 